\title{
EURÍPIDES Y LA PUESTA EN CUESTIÓN DEL LOGOS SAGRADO Y DEL LOGOS SECULARIZADO
}

Juan Carlos Rodriguez Delgado

Universidad del Pais Vasco

Para hablar de la Grecia clásica, es obligado hablar de la palabra instrumento capital de la vida pública de la polis. La democracia ateniense misma es inseparable de este estatuto privilegiado de la palabra que la convierte en instrumento político principal, por medio del cual se tratan y deciden todos los asuntos comunes, y del que pueden disponer todos los ciudadanos, con igualdad de derechos. A este tipo de palabra alude uno de los significados del término lógos, que hasta mediados del siglo $\mathrm{v}$ antes de $\mathrm{C}$., será intercambiable con mỹthos. Tanto uno como otro término aparecen usados indistintamente no sólo para referirse a la palabra persuasiva, sino también al discurso de razón, así como a los relatos tradicionales, a las palabras de los aedos'.

En la época arcaica, en la que la transmisión de los conocimientos y creencias que cohexionaban a la sociedad se realizaba oralmente, la palabra desempeñaba un papel importante, sobre todo, en tres campos que correspondían a tres funciones sociales fundamentales: la poesía, la mántica y la justicia. El poeta, aoidós, era el que cantaba las historias de los dioses y de los héroes, en las que se encontraba encerrado ese conjunto de saberes, creencias y patrones de comportamiento de la comunidad. El privilegio de estos aedos es el de participar de una Memoria sacralizada, una omniscien-

' Sobre esta cuestión de la primitiva intercambiabilidad de los términos mỹthos y lógos y su posterior diferenciación M. DETIENNE, cap. III de L'invention de la mythologie. Gallimard, Paris 1981 (traduc. española, La invención de la mitologia, pp. 62-82. Península, Barcelona 1985); Furio Jesı, cap. I de Il mito, Isedi, Milán 1973 (traduc. española, Mito, pp. 15-31. Labor, Barcelona 1976). 
cia de carácter divino. Así las palabras, los mỹthoi o lógoi, que salen de la boca de estos personajes, fundamentales en la sociedad arcaica, se caracterizan por una serie de rasgos, de los que, siguiendo a Detienne ${ }^{2}$ se pueden señalar como principales los siguientes: 1) el primero y más importante es la eficacia, ya que la palabra del poeta, igual que la del adivino, es realidad, acción (cuando Apolo profetiza, no es que anticipe el porvenir, sino que lo realiza, kraínei; 2) crea el orden cósmico, confiere sentido a los misterios del mundo que se le presentan al hombre; 3) se sitúa fuera del tiempo de los hombres y trasciende también a los hombres mismos que la cantan, pues este tipo de palabra no es la creación de un individuo, del poeta, sino que por boca de éste hablan potencias religiosas como la Memoria y las Musas; de esta autoridad que le confiere el ser inseparable de ese mundo sagrado, la palabra mítica ejerce un poder sobre los hombres (ahora bien, esta Persuasión está asociada a la ambigüedad).

Pero en esa misma sociedad arcaica, desde la época más remota, se desarrolla, en el grupo social formado por los hombres especializados en la función guerrera, otro tipo de palabra: la palabra-diálogo. Esos nobles de estirpe y hombres de guerra que son los héroes homéricos contaban como uno de los privilegios el derecho a la palabra. Esta importancia de la palabra aparece explícitamente reconocida en la Ilíada cuando en la educación que imparte Fénix a Aquiles se destaca como modelo de hombre el que conjuga en su persona la capacidad de ser «orador de discursos» y uhacedor de obrası $)^{3}$.

Esta palabra, en proceso de secularización, se diferencia de la palabra mítico-religiosa en una serie de aspectos: 1) en cuanto instrumento de deliberación ante acciones futuras es una palabra separada de la acción, pues la precede; 2) no adquiere su autoridad de un mundo transcendente y atemporal, sino de la aprobación o desaprobación que le otorgan los asambleistas; 3) es por tanto una palabra inscrita en el tiempo; 4) y no parece caracterizarse por la ambigüedad.

Como dice Detienne: «Será en las asambleas militares donde, por primera vez, la participación del grupo militar funde el valor de una palabra. Será alli donde se prepara el futuro estatuto de la palabra jurídica o de la palabra filosófica, de la palabra que se somete a la «publicidad» y que obtiene su fuerza del asentimiento de un grupo social» ${ }^{4}$.

${ }^{2}$ M. Detienne, Les maîtres de verité dans la Grèce archaique, Cap. IV, Masperó, Paris 1981 (traduc. española: Los maestros de Verdad en la Grecia arcaica, pp. 61 ss., Taurus, Madrid 1981).

${ }^{3}$ mýthōn te rétêr' émenai prēktêrá te érgón (Il. IX 44c).

4 M. DetIENNE, op. cit., p. 99. Aunque hay que matizar que esta palabra no es una palabra del todo secularizada, pues su capacidad persuasiva, además de residir en la habilidad de decir la palabra oportuna en el momento justo, también se fundamentaba en la referencia a la tradición mítica que le dotaba de autoridad, le confería legitimidad. Ejemplos de uno y otro caso son respectivamente Ulises y Néstor en la lliada. 
Con el desarrollo de la pólis, la reforma hoplita y la invención y progresiva difusión del alfabeto, se abrirá una crisis del pensamiento míticoreligioso paralelamente a un cambio en el estatuto de la palabra entre los siglos viII y IV a. C. ${ }^{5}$ De este modo nos encontramos en el siglo $\mathrm{v}$ con una sociedad en la que, aunque perdura, ya no es tan dominante el pensamiento religioso tradicional, y la palabra se desarrolla autónomamente sobre todo en dos direcciones diferentes: 1) como instrumento de persuasión, de poder sobre el otro; 2) como medio de poder sobre la realidad, o de conocimiento y explicación del mundo.

En la primera dirección se desarrollará la corriente retórico sofística, y en la segunda el pensamiento más específicamente filosófico.

En este contexto, Eurípides es, en el siglo $v$ ateniense, el personaje que cuestiona la palabra mítico tradicional, sin alinearse en ninguna de esas dos direcciones, en las que se revaloriza el poder de un logos secularizado. Es más frente a la creencia en el poder persuasivo y el poder cognoscitivo de la palabra, Eurípides subrayará la limitación e insuficiencia del logos en ambas dimensiones. Veamos, pues, el cuestionamiento en la obra de Eurípides de la palabra mítico-religiosa, del logos como instrumento de persuasión y del lógos como instrumento de aprehensión de la realidad del mundo.

\section{LA DESOCUPACIÓN DE LA PALABRA DE SU SENTIDO SAGRADO EN LA OBRA DE EURÍPIDES}

La cuestión del sentido del mundo estaba, para los antiguos griegos, ligada a un pensamiento religioso politésta que cumplía la función de proporcionar el conocimiento de los fundamentos «auténticos» de la vida y de los comportamientos vitales que de ellos se derivan. En el siglo v a. C., el siglo llamado de la Ilustración griega, en el que vivió Eurípides, se incrementó el desarrollo del lógos secularizado y la crítica a la religión tradicional se vio fomentada por gente somo los sofistas, uno de los cuales, Protágoras, se dice que leyó su tratado escéptico Sobre los Dioses en casa de Eurípides.

'Son de gran interés a este respecto los libros de E. A. Havelock, Preface to Plato, Harvard 1963, y The literate Revolution in Greece and its Cultural Consequences, Princeton 1982. Posteriormente se han desarrollado una serie de estudios en esta línea de prestar atención al paso de la oralidad a la escritura y sus consecuencias, de entre los cuales cabe citar por su interés el recientemente editado bajo la dirección de M. DETIENNE, Les savoirs de l'ecriture. En Grèce ancienne, Lille 1988.

- También se afirmaba que la lectura de este tratado había sido hecha en la casa de un tal Megaclides o en el liceo, y no por Protágoras sino por un personaje llamado Arcágoro, hijo de Teódoto (Diógenes Laercio, IX 54). 
Eurípides participó activamente, con su teatro en este cuestionamiento de las creencias religiosas tradicionales. La aparición de dioses olímpicos en las tragedias de Eurípides no debe llevarnos a engaño, pues el tratamiento de temas mitológicos, conocidos por la comunidad, era una de las constricciones que el género trágico imponía. Sin embargo, si leemos las obras de Eurípides, veremos que a pesar de estas constricciones y de la censura vigente en la Atenas de la segunda mitad del siglo $v$ a. $\mathrm{C}^{7}$ Euripides, a diferencia de los otros grandes trágicos, como Esquilo y Sófocles, opera como dinamitero de esas mismas creencias tradicionales, poniendo al descubierto el carácter de «doble», de proyección de pasiones «humanas, demasiado humanas", en el que se fundamentan las figuras divinas.

Afrodita y Eros, por ejemplo, en el Hipólito, son objeto de ese proceso de naturalización-humanización por el que se nos muestran, más que como seres superiores-divinos, como hipóstasis de los deseos amorosos que Fedra siente por su ahijado, y que en un primer Hipólito, rechazado por escándaloso o irreverente, aparecía aún más explícitamente afirmados por la misma Fedra como sentimientos realmente naturales y humanos.

En otras obras de Eurípides, los dioses aparecen, no sólo desolemnizadós, sino como auténticos malhechores. Ahí tenemos el Heracles o el Ión, la obra considerada como las más demoledoramente crítica respecto de la religión olímpica. En esta pieza no sólo es Apolo el blanco de los más duros ataques, sino que incluso, bajo la apariencia de una crítica a este dios délfico, lo que se pone en cuestión es todo el sistema de creencias míticas y el aparato ritual griego. En esta obra, las críticas de injusticia e ilegalidad que se dirigen a Apolo se extienden al conjunto del panteón olímpico (cf. vv. 436-453). Además de alcanzar a Apolo las críticas socavan los fundamentos más profundos de la religión griega. Este vaciamiento de poder de la palabra mítica, se observa en diversas obras del trágico. Incluso los Deux ex machina que aparecen al final de obras como Andrómaca, Electra, Heracles, Hipólito o

7 Cf. E. R. DodDs, Los griegos y lo irracional, Alianza Editorial, 1980, p. 180 y nota 63, donde señala que en una fecha situada entre el 432 y 434 a. C. se convirtió explícitamente en materia delictiva, además de la enseñanza de la astronomía, la no creencia en las divinidades; cf. también Luis GiL, La censura en el mundo antiguo (1961), Alianza Editorial, 1985², p. 55 ss.

En la biografia de Euripides elaborada por Sátiro se lẹe que «de Cleón el demagogo esquivó la acusación de impiedad (thềs aseheias) » (Vit. Eur., fr. 39, col. X). Aunque la asebeia, en sentido de sacrilegio, había constituido siempre materia delictiva, lo que resultaba una novedad era la prohibición, no sólo de la desatención del culto, sino también de la enseñanza antirreligiosa. Así, como señala DodDs (op. cit., p. 180, nota 63) la tradición coincide unánimemente en presentar los procesos entablados contra ciertos pensadores como fundados, no en sus acciones, sino en sus concepciones teóricas, como la de describir el sol como un objeto material, en el caso de Anaxágoras, o manifestar dudas acerca de los dioses en el caso de Protágoras. En lo referente a Euripides, contamos con el testimonio de Plutarco (De placit. phil., 7,2) en el que se observa que si Eurípides no manifestaba abiertamente sus opiniones era por miedo al Areópago. 
Las Bacantes, no sólo no eliminan, disminuyen o dan sentido a la desgracia y el sufrimiento, sino que, en ocasiones, lo acrecientan.

Pero lo que nos interesa destacar aquí es que Eurípides, al atacar directamente a Apolo, ataca, también la dimensión oracular de la palabra sagrada, que en él tiene a su máximo representante. Este dios es cuestionado en su estatuto de vidente del futuro. Se les niega explícitamente sus palabras el poder adivinatorio, el poder de manifestar «lo que es, lo que será, lo que fue" a los hombres. Deja de ser el dios que cuando profetiza, "realiza" (krainei), y se pone por tanto en solfa el ritual oracular.

En el prólogo de Ión, afirma Hermes que:

«Loxias (Apolo) ha estado conduciendo su destino hasta aqui y nada se le escapa, como es lógico. Cuando Juto entre en este templo, le entregará su propio hijo diciendo que es de él, a fin de que el joven marche a casa de Creusa y sea reconocido» (vv. 68 ss.).

Pero este destino que ha previsto el dios «que revela el futuro», no se cumplirá. Esta no correspondencia entre lo que el dios vaticina y lo que realmente ocurre, aparece manifiesta a través de la pieza, y queda explícitamente recogida en una parte de la intervención de Atenea, al final de la obra, en la que la diosa reconoce el incumplimiento del vaticinio de Apolo, cuando dice: «el soberano quería mantenerlo en secreto y que luego en Atenas descubrieras que ésta es tu madre y que tú eres hijo suyo y de Febo (Apolo)» (vv. 1566-67).

Hasta tal punto se pone en duda el poder adivinatorio de Apolo que el coro, tras el oráculo en el que aquél le dice a Juto que la primera persona que se encuentre al salir será su hijo, expresa su desconfianza y llama incluso mentiroso al dios: «no me dejo admirar por tu oráculo (thésphata) no sea que encierre engaño (dólon)" (vv. 685).

En Electra, cuyo argumento está tomado de una leyenda en la que la intervención de Apolo es relevante, el crimen que ésta y su hermano Orestes comenten en la persona de su madre para vengar la muerte de su padre Agamenón, y que en el relato mítico (cf. Esquilo) aparecía revestido de una respetuosa aureola sacra (el oráculo de Febo-Apolo), Eurípides lo desliga de toda relación religiosa.

No sólo Orestes califica de gran insensatez el oráculo de Apolo « Febo, grande es la insensatez que has pronunciado en tu oráculo». (v. 971) y se pregunta «¿no me habrá aconsejado esto un alástor, tomando la figura del dios?», sino que además (y esto es decisivo) el Coro (v. 739 ss.) niega la maldición hereditaria de la casa de Atreo echando por tierra los cimientos religiosos sobre los que se erigía la concepción trágica de Esquilo: 
«Se dice - más poco crédito doy- que el Sol de aspecto dorado se tornó cambiando de posición ${ }^{8}$ para mal de los hombres, por castigar a los mortales. Los mitos que asustan a los hombres son convenientes para el culto de los dioses.»

La eliminación de ese soporte adivino del crimen es, justamente la innovación que Eurípides aporta en el tratamiento de este tema mítico. Con esto se evidencia que la intención del trágico es la de sacar a la luz lo absurdo de esta leyenda, haciendo aparecer así el matricidio como un crimen abominable. Incluso las Erinias aparecen en Orestes (248 ss.) como meras alucinaciones del matricida.

Estas críticas dirigidas particularmente a Apolo y sus oráculos, las encontramos en repetidas ocasiones también en el Orestes (vv. 76, 191, 28586, 417, 595-96, 955-56).

El escepticismo de Eurípides en relación al poder adivinatorio de la palabra oracular, le lleva a hacer de los adivinos blancos de su crítica e ironía. Contra lo que arremete particularmente Euripides es contra la mántica inductiva. Así, en Helena, oímos al viejo mensajero decirle a Menelao:

"Ahora veo qué falso (phaûla) y lleno de mentiras (pseudõn) es el arte de los adivinos (tà mánteōn). Ninguna sensatez hay en la llama que arde ni en los cantos de los seres alados. Necedad es pensar que los pájaros tienen deudas con los mortales» (744 ss.).

En Hipólito, Teseo proclama también parecida desconfianza (vv. 105859), así como Eteocles y Creonte en Fenicias (vv. 771-73; 971 ss.).

A parte del ataque al pretendido poder de conocimiento del futuro de la palabra de oráculos y adivinos, que se repite en otras obras (If. $A$. vv. 955-59), Eurípides denuncia también la inmoralidad y ambición de esos personajes (If. A. 529, Fenic. 855...). En Las suplicantes es denunciada también la posibilidad de interpretaciones interesadas de las palabras oraculares, (841-46). Lo mismo sucede en Fenicias (vv. 409-424).

- El mito cuenta que Tiestes, seduciendo a la mujer de Atreo, su hermano, le robó a éste el cordero de oro que le garantizaba la realeza y que era un regalo de los dioses. Enojado por este hecho Zeus previno a Atreo, por mediación de Hermes, de que conviniera con su hermano la recuperación de la realeza si el sol invertía su curso (cf. P. GRIMAL, Diccionario de mitologia griega y romana. Paidós, 1985, pp. 62-63). 
En resumen, la palabra mántica ya no es la palabra sagrada, sino una palabra sospechosa, denunciada por su impotencia adivinatoria y por su interesada utilización deshonesta.

Se podría objetar que no sólo nos encontramos, en el teatro de Eurípides, con adivinos que no adivinan, de los que se habla negativamente. Y para apoyar esta objeción se podría aludir al caso de la infalible Casandra (Troy. 488) o al de las bacantes que, poseidas por el delirio, ven el futuro (Las bacantes, vv. 298-302). Ahora bien, ambos casos coinciden en que el conocimiento del porvenir que obtienen, por ese indiscutible don de videncia intuitivo, es incomunicable. En el caso de Casandra sus palabras están condenadas a no ser creídas, a ser "vanas" (ákranta). En el caso de las bacantes la videncia que experimentan en el estado de trance no se recuerda posteriormente, como lo muestra el caso de Agave, que cuando recobra la consciencia no se acuerda de nada.

\section{EL CUESTIONAMIENTO DEL PODER PERSUASIVO DEL LOGOS}

El espectáculo de la condición humana y de las relaciones interpersonales que Eurípides nos presenta, no tiene el lógos como primera figura, a pesar de que éste intente monopolizar la escena en repetidas ocasiones. El poeta nos muestra personajes lacerados por conflictos interiores, librados por oscuras fuerzas, entre las que el logos, entendido como raciocinio, no desempeña ese papel dominante de guía y controlador de la conducta, que le adjudicaba la concepción de los partidarios del optimismo racionalista, sino que en unos casos se ve irremisiblemente desbordada por fuerzas emocionales, $y$, en otros, se subordina claramente a ellas.

Este es el caso, por ejemplo, de Medea, en la tragedia del mismo nombre, en la que esa derrota de la razón, del logos ante los sentimientos o impulsos, se refleja incluso explicitamente en las palabras que la protagonista, reconociendo lo condenable del infanticidio proyectado pronuncia: «sí, conozco los crímenes que voy a realizar, pero mi pasión (thymós) es más poderosa que mis reflexiones (boulemáton) (vv. 1078-79).

Este destronamiento del lógos, al que asistimos en el interior de Medea, se produce igualmente en lo que se refiere a las relaciones interpersonales, en su dimensión de poder sobre el otro. En el agón entre Medea y Jasón (vv. 475 ss.), Eurípides pone en práctica las técnicas propias de las escuelas de elocuencia. Jasón, tras las acusaciones de Medea, empieza su defensa retórica subrayando que va a echar mano de todos los recursos de la retórica (vv. 522 ss.).

En este agón el dominio mayor de la palabra, la superioridad en elo- 
cuencia, corresponde claramente a la intervención de Jasón, como lo reconoce expresamente el corifeo, al acabar aquél su parlamento, cuando dice: «Jasón, bien has adornado (ekósmèsas) tus palabras (lógous)» vv. 576).

Pero esta superioridad retórica no supone ningún cambio en la actitud hostil de Medea para con él, ni le impide al corifeo añadir «pero me parece, aunque voy a hablar contra tu punto de vista, que has traicionado a tu esposa y no has obrado con justicia». Esto es, las recetas sofiticas no han persuadido, no han convencido ni al corifeo, ni a Medea, la cual incluso arremete contra éstas de un modo manifiesto?.

En el desarrollo de la tragedia este agón, entre Medea y Jasón, no resuelve nada. Medea sigue alimentando sus deseos de venganza. Jasón persiste en la idea de casarse con la hija del rey Creonte. Pero lo que sí nos muestra es un ataque directo a las concepciones sofisticas, optimistas en cuanto a los argumentos racionales, y a la idea de una naturaleza humana basada en el logos. Que el atacar la soberanía del logos (misología) era atacar a la concepción ilustrada de la naturaleza humana queda patente en el Fedón (89 d), donde Platón, por boca de Sócrates, habla del odio a los argumentos o misología, poniéndola en relación con la misantropía misma ${ }^{10}$.

Al comparar el teatro de Eurípides con el de los otros trágicos, salta a la vista en aquél la novedosa introducción de largos parlamentos razonados, de argumentaciones y contraargumentaciones, que constituyen los diálogos entre personajes. Ahora bien, estos discursos racionales, a pesar de acaparar la atención del espectador, se revelan incapaces de dominar situaciones, conducir comportamientos o modificar conductas $u$ opiniones. Podemos considerar como obras en las que más claramente estos razonamientos llegan a monopolizar la escena, además de Medea, Los Heraclidas, Hipólito, Hécuba, Las Troyanas y Helena.

En Los Heraclidas, el agón entre el heraldo, que quiere llevarse a los descendientes de Heracles a su país para matarlo, y Yolao que, junto con los demás Heraclidas suplicantes, pide protección a Demofonte, soberano de Atenas, se desenvuelve también a la manera de las técnicas sofisticas. El heraldo argumenta, promete ayuda, alude al deshonor, amenaza al rey de Atenas y termina descalificando las posibles ventajas que obtendría éste si ayudara a los Heraclidas (vv. 68 ss.).

9

«Para mi, quien es injusto y, al mismo tiempo, de talante habilidoso (sophós) en el hablar, merece el mayor castigo, pues ufanándose de adornar la injusticia con su lengua se atreve a cometer cualquier acción, pero no es excesivamente sabio" (vv. 579 ss.).

10 «No vayamos a hacernos misólogos — dijo él- como los que se hacen misántropos. Porque no se puede padecer mayor mal que el odiar los razonamientos (lógous). Y la misología se origina del mismo modo que la misantropía". (Fed., $89 \mathrm{~d}$ ss.) 
Yolao replica a los argumentos del heraldo, alude al parentesco común con Demofonte e insta a éste a devolver ahora el favor que le hizo Heracles al sacarle del Hades; alude a la mala fama que le acarreará el abandonar a unos suplicantes, y termina rogándole compasión.

Después de escuchar las dos intervenciones, Demofonte opta por ayudar a Yolao y a los Heraclidas, por tres razones que él mismo explica:

- por Zeus, a cuyo altar se acogen los suplicantes;

- por el parentesco y el favor debido a ellos;

- por el honor, pues «si dejo que este altar sea saqueado a la fuerza por un extranjero, parecerá que no habito en una tierra libre» (vv. 236-246).

Como se ve, Demofonte, toma partido decididamente por los suplicantes. Ahora bien, esta resolución, racionalmente adoptada, de abrazar la causa de los Heraclidas y defenderla, aún a costa del enfrentamiento armado con los argivos, se desvanece cuando las profecías exigen a Demofonte que «degüelle en honor a Core, hija de Démeter, una doncella que sea hija de padre de buen origen». Ante esto, el rey dice: «yo tengo, como ves, un afán muy grande hacia vosotros, pero no voy a matar a mi hija ni obligaré a ningún otro de mis ciudadanos a pesar suyo».

Es decir, la fuerza de la argumentación, del logos anterior, a favor de los suplicantes, se viene ahora abajo. Y en este caso el logos se estrella contra una situación provocada por una creencia, la creencia en el oráculo. Esto es, un distinto modo de considerar la vida es un abismo que el logos no puede cubrir.

Esta imposibilidad de comunicación, esta impotencia de la palabra cuando las visiones del mundo difieren, vuelven a aparecer en el Hipólito. Este joven, que da nombre a la pieza, es un casto eremita que enfoca su vida en una comunión mística con la naturaleza y la diosa Ártemis. Fedra, sin embargo, enferma en deseos amorosos por este joven hijastro, deseos que se esfuerza en reprimir y ocultar. A ella misma, tras una intervención típicamente retórica de la nodriza, le oímos criticar precisamente «los discursos demasiado bellos» (oi kaloi lian lógoi v. 487). En esta tesitura, la nodriza aconseja a su ama Fedra, preocupada por su fama, de este modo:

"iA qué viene este hablar tan serio? Tu no necesitas bellas palabras, sino ese hombre. Hay que referírselo lo antes posible, revelándole sin rodeos lo que te sucede» (Hip. 492 ss.). 
Y la nodriza se encarga de transmitir a Hipólito este lógos euthýs, estas francas palabras, las cuales no sirven para establecer ningún diálogo, sino que provocan una reacción de ira, una explosión de insultos en el joven místico, que llama a la nodriza «alcahueta de desgracias, traidora del lecho de su señor». Apaciguado el joven, se entrega a un largo monólogo en el que da rienda suelta a su odio hacia el género femenino (vv. 616-668).

La visión de la vida que mueve a Hipólito, le hace impermeable al logos. Toda palabra que ponga en entredicho su visión mística y casta de la vida, no es una palabra, un vehículo de comunicación, sino que es según este joven, algo que mancha, como se ve cuando refiriéndose a las palabras de la nodriza dice:

«Yo me purificaré de esta impureza con agua clara, lavando mis oídos. ¿Cómo podría ser yo un malvado, yo que, por sólo escuchar semejantes proposiciones, me considero impuro?» (vv. 653-57).

Somos espectadores de la misma impotencia comunicativa de la palabra en Hécuba (vv. 251 ss.). Aquí nos encontramos con el agón dialéctico entre esa mujer y Ulises. El parlamento de Hécuba, que quiere salvar a su hija de ser víctima de un prometido sacrificio de los helenos a Aquiles, despliega argumentaciones y todo tipo de recursos retóricos. Empieza señalando lo inadecuado de la elección de su hija como víctima, pues no tiene culpa alguna de la guerra en la que murió el héroe griego, ni tampoco es la más bella de las esclavas (vv. 260 ss.).

A continuación de este sutil razonamiento, Hécuba utiliza toda clase de efectos para salvar la vida de su hija. Le exige a Ulises que le devuelva ahora el favor que le hizo, al no denunciarlo en Troya, cuando se enteró que estaba disfrazado como espía en la ciudad. Y Hécuba termina (vv. 279-296) aludiendo a lo mucho que supone su hija para ella: «es para mí alivio, ciudad, nodriza, bastón, guía del camino", subrayando la necesidad de «que los que manden no manden lo que no se debe» (v. 282), y «que es odioso matar a unas mujeres que no matásteis antes al arrancarlas de los altares sino que las compadecísteis". Y termina diciendo que: "una ley hay igual entre vosotros, tanto para libres como para esclavos».

El corifeo, ante este despliegue de recursos verbales destinados a conmover, no puede sino expresar: «no existe una naturaleza humana tan dura que, al oír tus gemidos y el canto fúnebre de tus largos lamentos, no derrame lágrimas» (vv. 297-300). Es decir, la intervención de Hécuba es irresistible. Sin embargo, no hace mella en Ulises que responde con otro parlamento destinado a defender su decisión tomada, y en el que argumenta que hay 
que honrar a Aquiles, que hay que mantener el premio ejemplar de la fama y las honras para los valerosos guerreros, y que también los helenos sufren las desgracias de la guerra.

A pesar de la fuerza superior de los razonamientos y de la capacidad persuasiva de la intervención de Hécuba, Ulises no cambia de postura. Este héroe mantiene su decisión, aunque sofísticamente aparenta que le está dando la razón a Hécuba, pues después de esto dice: «Yo, tu vida, por la que logré entonces estoy dispuesto a protegerla y no digo otra cosa», añadiendo a continuación "pero lo que dije ante todos no lo voy a negar» (vv. 304305).

La inutilidad de los razonamientos es reconocida por Hécuba cuando exclama: « $\mathrm{O}$ h hija! Mis palabras (lógos) se han ido al éter arrojadas en vano (mátén) por evitar tu muerte» (vv. 334, 335). Volvemos a encontrarnos con la imposibilidad del lógos de salvar el abismo entre dos diferentes visiones del mundo. Hécuba revela un comportamiento fundado en unos sólidos valores de igualdad, gratitud y correspondencia hacia el benefactor. Pero sus argumentaciones se han estrellado contra un comportamiento basado en una concepción utilitarista, guiado por valores oportunistas, al servicio de los cuales se echa mano de la retórica.

Más adelante en esta tragedia, Hécuba en medio de un largo parlamento retórico pronuncia claras palabras de reconocimiento de la soberanía de la Persuasión y de invitación al aparendizaje del arte de la retórica. Sin embargo este reconocimiento del arte de los sofistas queda descalificado a continuación, cuando Agamenón, en su intervención, pone de manifiesto que la maestría retórica que Hécuba acaba de poner en juego no ha logrado convencerle. Es decir, ante el deseo de Agamenón de ser reconocido por los aqueos y ante el miedo a verse desprestigiado y calumniado por ellos, el poder persuasivo de la retórica naufraga una vez más (vv. 857-863).

La conciencia de la limitación e insuficiencia del lógos aparece también reflejada en las palabras que Andrómaca, pronuncia al principio de la tragedia que lleva su nombre, en contestación a la acusación que Hermione le dirige. Oímos decir a Andrómaca que: «los orgullosos soportan con amargura los razonamientos superiores (toùs kreissous lógous) de parte de gente inferior (tòn elassónōn hýpo)" (vv. 189-190). Esta afirmación está muy lejos de ese principio de Protágoras según el cual el convencimiento, la persuasión, se logra por medio de la técnica retórica de «convertir el argumento débil en fuerte»" ${ }^{11}$.

" tòn héttõ lógon kreittō poieîn (Diels-KRANZ, Vorsoer. $80 \mathrm{~B} 6 b$ ) cf. V. DJ BenEDETTo, Euripide teatro e societá. Einaudi, Turin 1971, p. 90, donde señala que en Andrómaca, está claro que la palabra no basta, que lo que cuenta son las reales relaciones de fuerza. En el cap. IV de este libro ("Condizionamenti oggettivi e demistificazione del logos») Di Benedetto carga el acento en la limitación del lógos frente a las relaciones de fuerza y los condicionamientos 
Otra ocasión en la que Eurípides nos presenta el fracaso de la palabra como instrumento de entendimiento entre las personas aparece en Las $\mathrm{Fe}$ nicias. Por una parte Yocasta se esfuerza por apaciguar los exaltados ánimos de los hermanos enfrentados, proponiéndoles resolver el litigio, tranquilamente, mediante el uso desapasionado del lógos (vv. 452-65). Sin embargo los razonamientos de Yocasta caerán en saco roto. Polinices expone los hechos tal como han sido, sin adornos retóricos, pues dice: «sencillo es el relato (mŷthos) de la verdad (iès aletheias). Explica el pacto acordado mediante el cual él salió voluntariamente del país a condición de volver, para gobernarlo, pasado un año. Polinices exige a su hermano Eteocles que cumpla lo acordado. Sin embargo Eteocles, tras referirse a la inevitabilidad de «la discordia de ambiguo lenguaje» que se alimenta del conflicto de intereses y pareceres, afirma que:

En realidad no hay nada idéntico ni ecuánime para los mortales al margen de los nombres (onómasin) de hecho no existe tal realidad.

Con que yo, madre, hablaré sin ocultar nada. Llegaría hasta los astros del cielo y bajaría al fondo de la tierra, si fuera capaz de realizar tales acciones, con tal de retener a la mayor de las divinidades: la Tiranía (vv. 502-508).

El corifeo recrimina esta actitud de Eteocles diciendo: «No conviene hablar bien (eũ légein) en favor de hechos no buenos. Pues eso no es hermoso, sino amargo para la justicia» (vv. 526-28).

Yocasta también lanza su crítica a Eteocles: «iPor qué te abandonas a la peor de las diosas, hijo mío, a la Ambición?» (531). Y continúa haciendo una apología de la equidad.

A pesar de lo justo del racionamiento de Polinices, de la intervención del corifeo, y de los argumentos de Yocasta, su hijo Eteocles, sordo a todo ello por su ambición de poder, no cede el gobierno del país a su hermano y prefiere afrontar el combate contra él.

En todas estas escenas, si algo queda claro es el poco o nulo valor de las argumentaciones y de la retórica, en determinadas ocasiones. Eurípides aparece una vez más como el aguafiestas de ese optimismo ilustrado basado en la confianza en el lógos, como factor dominante de la naturaleza e ins-

\footnotetext{
objetivos cuando, a nuestro modo de ver, en el teatro de Eurípides está puesto de manifiesto que el diálogo de sordos, la impotencia del lógos se debe también a la adhesión a una creencia o a determinados sentimientos de los personajes.
} 
trumento capaz de modificar las voluntades y actitudes humanas. El interés del trágico parece ser el de subrayar la inoperancia de la elocuencia del lógos persuasivo, cuando se enfrenta a las ocultas fuerzas del thymós que son los verdaderos resortes de la acción de sus personajes.

Una prueba de ello reside también en que, en los casos en los que parece demostrarse la validez de la persuasión verbal, nos encontramos con un thymós ya predispuesto a ser convencido, como es el caso de Teonoé en Helena y de Penteo en Las Bacantes.

En Helena parece demostrarse la validez de la persuasión dialéctica, pues Teonoé termina siendo convencida por los discursos de Helena y de Menelao. Ahora bien, en este caso no existe de antemano ni odio, ni ninguna disposición emocional en contra, por parte de Teonoé. Muy al contrario se nos presenta a ésta como a una joven piadosa inclinada al bien, como ella misma lo reconoce al explicar su decisión de ayudar a Menelao con estas palabras:

\author{
«... nací piadosa y quiero seguir siéndolo... \\ Dentro de mí se alza, desde mi nacimiento, un \\ magno santuario de justicia; por ese sentido \\ de la equidad que he recibido de Nereo, in- \\ tentaré salvar a Menelao» (v. 999 ss.).
}

En la pieza teatral que lleva por título Las Bacantes, Penteo que se ha quedado solo asumiendo una obstinada postura de prohibir a toda costa la celebración de los ritos dionisíacos en el país que gobierna, termina siendo convencido por Dioniso para acudir de voyeur a ellos. Lo que a primera vista puede parecer un triunfo de la persuasión de Dioniso, en una lectura más atenta se nos revela, sin embargo, como el resultado de la fuerza de un deseo reprimido del propio Penteo. Es una atracción erótica lo que impulsa principalmente al rey tebano a modificar su postura. La visión exclusiva y obsesivamente sexual que Penteo tiene del dionisismo, y que aparece expresada desde su primera aparición en escena, nos muestra la proyección de un prejuicio en el que se revela una sexualidad reprimida ${ }^{12}$. La fuerza de

12 En los versos 221-225, Penteo nos presenta su personal descripción de estos ritos: «Llenas de vino están en medio de sus reuniones místicas las jarras; y cada una por su lado se desliza en la soledad para servir a sus amantes en el lecho (eunaĩs arsénōn) con el pretexto de que son, sí, iménades dedicadas a su culto! Pero anteponen Afrodita a Baco». Más adelante, en los versos 234-37. Penteo se refiere a Dioniso como a un típico seductor, asociándole a la sensualidad que los atenienses atribuian a los paises orientales: "Que lleva una melena larga 
estos impuls̀os escondidos se transluce en las palabras de Penteo que después de decir que daría: «infinito peso en oro» por ver a las bacantes sentadas en los montes y embriagadas, preguntarle Dioniso: « $i Y$ verías con gusto lo que para ti es amargo?» (v. 815) responde: «iTenlo por cierto!» (v. 816). Y más adelante vemos aflorar en el rey tebano ese mismo deseo reprimido, que es el que le empuja a cambiar de postura, cuando dice: «Pienso que deben como pájaros estar en sus camas, en amorosos abrazos» (vv. 957958). La poderosa influencia de este deseo le lleva a Penteo a un estado de impaciencia tal que le hace pedir a Dioniso que le conduzca inmediatamente a contemplar a las ménades (v. 820). Así pues, el pretendido poder del lógos persuasivo se transfiere al dominio del oscuro mundo subjetivo, ante el cual aquél no juega más que el papel de humilde servidor, como reconoce el mismo Dioniso cuando, dirigiéndose a Penteo, profiere las siguientes reveladoras palabras: «Nosotros, que tenemos que servirte» (v. 932). No está, pues, en las palabras de Dioniso la fuerza persuasiva que mueve a Penteo a ir a ver a las bacantes, sino que son principalmente las fuerzas ocultas en el corazón del joven rey las que le empujan a ello.

Esto es, la aproximación euripidiana a los personajes, a la vez que se empeña en presentarnos la naturaleza humana como conflictiva y dinámica, en su realidad vivencial, pone límites a la pretendida soberanía persuasiva del logos y rompe el cliché reduccionista que mutila al individuo humano al definirlo como esencialmente racional.

y perfumada de bucles rubios, de rostro lascivo, con los atractivos de Afrodita en sus ojos». Cf. J. A. LA RuE «Prurience uncovered: The psychology of Euripides' Pentheus», $C J, 63$ (1968), 210-214, donde se destacan las connotaciones eróticas de la descripción física del pelo largo, ojos color de vino (oinōpas), y del verbo synginetai (v. 237) del que ya observaba Dodds su carácter de eufemismo utilizado en lugar de "relación sexual», y otras expresiones y términos con esta destacada connotación erótica.

Penteo termina esta primera intervención aludiendo a los perversos misterios (teletàs ponéràs) en los que, a su modo de ver, el uso del vino no tiene otra función que la de propiciar el desenfreno sexual: «Porque a las mujeres, en cuanto en un banquete festivo se les da el brillante fruto de la vid, ya no pueden pensar nada limpio (hygiès oudèn) de tales ceremonias" (vv. 250-262). La repetición de estas ideas al principio y final de su monólogo no hacen sino dejar patente su obsesión por el sexo, que se reflejará en otras ocasiones a lo largo de la obra (cf. vv. 352-354; 453-459). 
Nietzsche, en su libro El nacimiento de la tragedia, nos presenta a Eurípides como portavoz de un racionalismo optimista, prepotente, antitrágico, haciéndole partícipe de una visión del mundo originariamente socrática. Esta concepción de la realidad que, según Nietzsche, asocia a Eurípides con Platón ${ }^{13}$, afirma:

1) Que sólo mediante la razón podemos acceder a la verdad.

2) Que el mundo (lo que existe) tiene una estructura racional.

3) Que los errores intelectuales o las faltas morales se producen cuando no ejercitamos la capacidad racional que nos es propia a los humanos.

Pues bien, la impresión más viva que una lectura atenta y desprejuiciada de las tragedias de Eurípides nos produce, hace añicos ese retrato que Nietzsche nos pinta del poeta. Por lo que llevamos visto, la negación del tercer punto en el teatro euripideano es de una evidencia aplastante.

La visión del mundo y del hombre que aparece en este teatro es, precisamente, una de las negaciones más radicales que se han dado, en el pensamiento griego antiguo, de esos tres presupuestos del optimismo racionalista. Ya, en 1929 Dodds, en un artículo titulado «Euripides the irratio nalist», pone algunas pegas a esa visión nitzscheana del teatro de Eurípides.

Si más allá de las citas de cantos o parlamentos, entresacados de su obra, leemos las tragedias de Eurípides, veremos la relevancia que adquiere la aparición, en su desnudez más escalofriante, de ese mundo oscuro, no sólo de las pasiones, sino de la vida en general, cuya fuerza loca aniquila la ilusión de la superioridad e infalible capacidad controladora de las instancias intelectuales humanas. El mundo que aparece en escena es el mundo en el que son actores principales lo sinsentido, lo racionalmente indomeñable, esa dimensión que desborda todo orden y se sitúa fuera, más allá y más acá de la cadena racional de causas y efectos.

La emergencia de lo absurdo, con que amenazaba la crisis del tradicional pensamiento mítico-religioso, había hecho movilizar en los siglos vi y v a. C., en Grecia, los recursos ordenadores de un lógos secularizado. Sin

13 «Euripides se propuso mostrar al mundo, como se lo propuso también Platón, el reverso del poeta "irrazonable") (p. 114, op. cit.). 
embargo è el teatro de Eurípides asistimos a un creciente striptis que desnuda al mundo de su sentido religioso o racional, que priva al hombre, al revelarlo falaz, del consuelo del conocimiento, aniquilando incluso la confortable creencia sofística en el poder del lenguaje (poder sobre el otro), como hemos visto.

Es decir, en este exilio del mundo de lo divino que se impone Eurípides, las sombras predominan sobre las luces. El rebasamiento de la razón, que hemos visto reconocido en las palabras de Medea, se enseñorea de ese mundo abisal de la psyché en el que Eurípides nos sumerge también a través de personajes como Fedra, Creusa, Orestes, Agamenón, etc.

De este desorden de la psyché en la que la racional tiene un precario poder, Eurípides pasa a preocuparse del desorden del mundo en el que el individuo está integrado. Según va avanzando en su obra, va en aumento la preocupación del trágico por mostrar a personajes enfrentados a los avatares de un juego caprichoso, totalmente ajeno a cualquier orden cósmico. Las obras de Eurípides nos instan a reconocer, bajo la epidermis de los símbolos culturales, lo abisal de la naturaleza, el reino de la inestabilidad, de lo inescrutable, de lo inesperado, de lo sinsentido, que se manifiesta tanto en el individuo, o a través del individuo, como en el mundo, del que, sólo por ilusión, creemos a aquél autónomo, superior y controlador.

A partir de Hécuba, en algunas de las tragedias euripedeanas, la $T \dot{y} c h e$, el azar, se enseñorea de la escena. El poder supremo parece residir en, o, mejor dicho, confundirse con el azar, en relación al cual no valen ritos, ofrendas, ni veneraciones. A este poder ineluctable, a este azar no compatible con la idea de providencia, que incluso llega a expresarse explícitamente con la metáfora del «golpe de dados» (Elec. 1100-1101; Or. 603) es a lo que señalan, cada vez en mayor medida, no sólo la trama de las tragedias de Eurípides, sino también su innovadora estructura.

Uno de los recursos por medio del cual Eurípides nos señala hacia ese vacio de sentido, es el de la utilización, por otra parte obligada en la tragedia griega, de símbolos o significantes divinos privándoles, al máximo, de sus resonancias míticas y diluyéndolos en la ambigüedad más inmanejable. Además de este procedimiento, que se refleja en expresiones del tipo «Zeus -quienquiera que sea-", "lo divino, lo que quiera que sea» ${ }^{14}$, nos encontramos en el teatro euripideano, con intervenciones que explícitamente subrayan la soberania del azar, como hasta entonces no había sido hecho en la tragedia griega ${ }^{15}$. Así Teseo, ese modélico ciudadano y ejemplar amigo, le habla a Heracles, al final casi de la tragedia que lleva este nombre:

14 "Zeùs d', hóstis ho Zeús" (Her., 1253); "hó ti pot'ára tò daimónion» (Bac., 896).

15 Supl., vv. 210, 552, 608 ss., 734; Elec. en v. 610, el Viejo le dice a Orestes, refiriéndose al éxito de la empresa: «depende totalmente de ti y del azar»; Or., vv. 976 ss., etc. 
«Nadie está libre de los golpes del azar (taîs týchais), ni los hombres, ni tampoco los dioses, si no mienten los cantos de los poetas. ¿Es qué no han trabado entre sí uniones que no se ajustan a ninguna ley (nómos). No han encadenado a sus padres por ambicionar el poder? Sin embargo siguen ocupando el Olimpo y se les perdonaron sus yerros. Así pues ¿Qué decir si tú, que eres mortal, consideras insoportable los golpes del azar (taîs týchais) y los dioses no?» (Heracles, vv. 1312-21).

Aquí se identifica "azar» (o "fortuna») con "ausencia de ley" (oudeis nómos). Se puede decir que, tal como aparece en este párrafo, el azar es algo, no sólo situado por encima de los dioses míticos, sino también anterior a ellos, que son los que introdujeron el orden, la ley, es decir, los que conjuraron el caos. En Ion, el joven servidor de Apolo reconoce también la soberanía del «Azar (Týchēe), que trastocas la condición de miles de hombres y haces que sean desventurados y de nuevo tengan éxito» (vv. 15121513).

Es cierto que, en el teatro de Eurípides, nos podemos encontrar con que una suerte es enviada por un theós o por un daimon ${ }^{16}$ y que también pueden aparecer utilizados de manera intercambiable, términos referidos a divinidades y al azar ${ }^{17}$. También "destino" y "suerte» aparecen, en ocasiones, confundidas $^{18}$. De todos modos, a parte de la metáfora del «golpe de dados» ${ }^{19}$ que así lo indica, nos encontramos en las obras del poeta con reiteradas intervenciones en las que distintos personajes expresan una noción de azar incompatible con la de providencia ${ }^{20}$.

${ }^{16}$ theós en Her., vv. 309 y 1393; Elec., vv. 890, etc.; daimon en Her., vv. 934-935; Med., v. 671; Hip., 832; If. T., v. 876, etc.

${ }^{17}$ "Nûn d' hòs éoike, têi týchèi douleutéon" (Her., 1357). Más adelante Heracles, consciente de ser perseguido por Hera, coincide con Teseo, sabedor también de este acoso, en atribuir lo que pasa a los "golpes del azar" (v. 1393).

${ }_{18}$ Fen., 1202, If. A., 1403 y 1136; en If. $A$., v. 864, el predominio de la fortuna aparece marcado en menoscabo de las divinidades.

${ }_{19}$ El., 1110-1101; también, Or., 603.

20 Asi oímos de boca de Taltibio, personaje que opta por el azar, esta pregunta retórica:

"iOh, Zeus! ¿Qué he de decir? ¿Acaso que tú miras a los hombres, o que, sin motivo, tienen en vano esa creencia falsa, pensando que existe el linaje de las divinidades, y el azar (týchēn) se ocupa de todo lo de los hombres?» (Hécuba, 488-91). 
Jacqueline de Romilly ${ }^{21}$ apunta a este respecto la evolución experimentada con relación a Esquilo, señalando el contraste que se da en los dos trágicos en la utilización de un mismo pensamiento:

«Esquilo había escrito así, de manera soberbia: "las vías del pensamiento divino llegan a su término por sombras impenetrables a toda mirada" (Supl. 93 ss.); ahora bien, esta reflexión acaba en súplica confiante. Euripides, escribe, a su vez, en versos más modestos: "Siempre la voluntad de los dioses toma caminos tenebrosos, y nadie sabe el mal que le espera" (If. $T ., 476-77$ ), pero ya no habla más que de desgracia; y el pensamiento se acaba con una constatación de desorden: "Porque el Azar nos conduce en un sentido incomprensible"».

Como dice esta autora «el misterio de lo divino nos deja cada vez más confrontados a los simples desórdenes del azar» (p. 29), y así en el teatro euripideano aflora repetidamente la incertidumbre y el absurdo de los acontecimientos en los que se ven envueltos los hombres. Además de la metáfora del "golpe de dados», nos encontramos con términos que señalan en esa dirección de confusión (taragmós, sýnchysis) ${ }^{22}$, y adjetivos como anómalos ${ }^{23}$, astáthmètos $^{24}$ que subrayan esa inconmensurabilidad, esa inaprehensibilidad. Las invocaciones de reconocimiento de la soberanía del azar son repetidas en distintas obras y en boca de distintos personajes ${ }^{25}$.

Cabría objetar que a lo que estamos haciendo alusión aqui es a una serie de afirmaciones de personajes teátrales con las que la identificación del autor no es exigida. Ahora bien, además de tales explicitaciones del señorio del

En Hipólito, después de irse éste maldecido, inmerecidamente, por su padre, el Coro pone en cuestión la providencia de los dioses cuando canta:

"Mucho alivia mis penas la providencia de los dioses ( $t a \dot{a}$ theōn meledé math') cuando mi razón piensa en ella, pero aunque guardo dentro de mí la esperanza de comprenderla, la pierdo al contemplar los azares (týchais) y las acciones de los mortales, pues experimentan cambios imprevisibles (állothen ameibetai), y la vida de los hombres, en perpetuo peregrinar es siempre inestable (polyplánétos)». (Hip., 1105-11).

J. DE Romilly, La modernité d'Euripide, PUF, Paris 1986, p. 29.

Cf. If. T., v. 573.

2." Fr., 681, 1 .

24 "variable", «no fijo» (Or., 976 ss.).

2s Hip., 1106-1110; Héc., 487.91; Ion, 1512-13, 1169 ss.; Med., 1231; Bac., 894-96. 
azar o las quejas que esta dimensión inmanejable produce ${ }^{26}$, que salpican la obra de Euripides, la misma estructura de una serie de obras refleja esa soberanía reconocida del azar. Las peripecias, los golpes de teatro, los sucesos imprevistos, el sobresalto, aparecen como innovaciones dramáticas que según avanza el poeta, en su labor creadora, utilizará con más frecuencia. Esa originalidad dramática, estos múltiples sobresaltos que quiebran la clásica continuidad de la trama trágica, responden a la profunda visión del mundo de Eurípides, que le hace distinguirse de los otros trágicos.

Que «el teatro de Eurípides vive al ritmo de la sorpresa» (Romilly) se puede constatar remitiéndonos como ejemplos más claros, a tres tragedias que se encuentran, por ello mismo, en el límite del género: Ión, Ifigenia entre los tauros y Helena ${ }^{27}$. En estas tres tragedias la combinación de intrigas, el enredo y el azar dominan toda la acción. En Ion, además de su trama de obra de enredo ${ }^{28}$, de aludirse explícitamente a Tyché como supremo poder (vv. 1512-1513), y de ser por puro azar como se salva de morir envenenado Ion (vv. 1169 ss.), la figura de Apolo en su vertiente de dios que «les manifiesta el presente y el futuro a los hombres» es, como hemos visto, puesta en solfa. El suspense, lo insospechado, destacado en la misma estructura de esta obra, aparece más enfatizado aún al irrumpir, echándolo abajo, en el dominio dador de sentido por excelencia: el oráculo délfico, el dominio de Apolo. En Ifigenia entre los tauros y en Helena, los errores, el azar y la sorpresa también tienen un marcado protagonismo, desconocido en las obras de los otros trágicos. Así también, en Electra y Orestes la intriga y el azar dominan la acción. Esta supremacía de lo impredecible y de la sor-

26 "Así son las cosas humanas, ninguna permanece en su sitio (oudèn en tautōi ménei)" (Ión, 969; cf. tb. Or., 1504).

27 Estas tres tragedias se sitúan entre el 418 y 412 a. C.

${ }^{28}$ Apolo, tras seducir a Creusa, reina de Atenas, la dejó embarazada. Creusa dejó al hijo de esta unión a los pies de la Acrópolis, de donde lo recogió Hermes para llevárselo a Delfos donde fue criado y hecho sacristán del templo. Creusa y su marido Juto, que ignora la relación de su mujer con Apolo y que quiere tener un hijo, llegan a Delfos. Apolo intenta hacer pasar al joven Ion por hijo de Juto. Creusa celosa intenta envenenar a este hijo que cree que su marido ha tenido con otra. El joven que se salva por azar de morir envenenado, quiere matar a Creusa, a quien reconoce como madre justo en el momento en que se dispone a realizar el crimen. Como comenta J. DE ROMILLY:

"On est là en pleine comédie d'intrigue. Tour le monde vit dans l'erreur. Et il faut une intervention divine de dernière minute pour éviter le désastre. Enfants perdus et retrouvés, maris ignorants, coups réciproques: il ne s'agirait plus d'una tragédie si l'on ne passait à deux reprises aussi près de la mort et si la souffrance de Créuse, dépossédée dans sa tendresse maternelle, ne marquait ce que de telles intrigues peuvent coûter aux pauvres humains) (La Tragédie Grecque, Paris 1970 , p. 146). 
presa se refleja, por otra parte, en esa estrofa que sirve de final a tragedias como Alcestis, Medea, Andrómaca, Helena y Las Bacantes ${ }^{29}$.

Este mundo gobernado por lo arbitrario que nos muestra el poeta es, además de desconcertante, doloroso. En este sentido, Eurípides coincide con los otros trágicos en afirmar el sufrimiento y el dolor como partes consustanciales de la vida, en subrayar la fugacidad o inexistencia de la felicidad, pero remarcando con más fuerza la constante inminencia de las desgracias, los rápidos cambios de suerte, y desarraigando el problema del mal de un mundo de sentido religioso en el que estaba inserto. Las fuerzas de lo sin sentido no encierran ninguna justicia, ni comparten ninguna unidad, como lo muestra la utilización dramática en Las Bacantes de la figura más polimórfica e inmanejable de los dioses griegos: Dionisos. A esta figura, tal como aparece en la tragedia, difícilmente se puede referir una idea de orden o de justicia superior. La invitación al abandono de la búsqueda de un sentido trascendente aparece en palabras del Coro:

«La ciencia de los sabios no es la sabiduría (tò sophọn d'ou sophia). Ni tampoco lo es meditar sobre lo no humano (tò mí thnèta).

¡Breve es la vida! Por eso, ¿quién puede cosechar el pre-sente ( $t a \grave{a} p a-$ rónta), si persigue lo infinito (megála)? Ésas son actitudes, en mi opinión, de mortales enloquecidos» (Bac., 396-401).

La sabiduría de Eurípides, y su eterna actualidad, consiste en señalar, por medio de sus piezas teatrales, más allá de los límites de lo culturalreligioso, hacia ese mundo de experiencias que supera y altera el ordenamiento con el que nos representamos la vida, hacia ese reino de la contradicción que no entiende de fronteras entre mundo exterior e interior, sujeto-objeto, y otras muchas dualidades esenciales del pensamiento filosófico y científico. El teatro de Eurípides nos muestra esa máscara risueña de Dioniso, pero que a la vez es trágica (como la imagen de Shiva hindú sonriente y a la vez adornada con un collar de calaveras); ese rostro que ni en esta contradicción descansa, siendo, al mismo tiempo, toro, león, serpiente u otra fuerza, cuya naturaleza, consiste en escapar a toda atadura y

29 "Muchas son las formas de lo divino (tōn daimonión) y muchas cosas realizan los dioses contra lo previsto (aélpōs). Lo que se esperaba (tà dokéthénta) quedó sin cumplir, y a lo increíble (tôn d'adokètón) encuentra sentido (póron éüre) la divinidad. De tal modo ha concluido este draman. 
transgredir todo encasillamiento. La sabiduría de Eurípides consiste en señalar hacia ese rostro de «lo otro», ver al individuo disuelto en ese desconcertante mundo, (como pez que no puede escaparse del océano para mirarlo desde fuera sin destruirse). Eurípides, a través de su teatro, se remonta hasta las fuentes profundas de la vida, perplejo ante las fuerzas inmanejables que alli se ocultan, y que atraviesan la naturaleza profunda de todo ser viviente.

Y llegados a este punto, destronado el lógos de su soberanía como lógossagrado, como lógos retórico-persuasivo y como lógos filosófico-científico, cabría preguntar qué valor le da entonces Eurípides a la palabra, a parte de su utilización en este juego estético-activo de desocupar el mundo y la vida, del sentido. Esto sería ya otro tema. Pero puede apuntarse que, liberada de toda trascendencia o ilusión de omnipotencia, la palabra queda revalorizada, no como pretendida soberana, sino como sierva, participando en distintos «juegos de lenguaje», que además de producir un goce estético nos pueden situar en una nueva forma de experiencia de conocimiento que libere potencialidades de comprensión real. 